\title{
Variação e mudança em nomes de jogadores da Seleção Brasileira
}

\section{Variation and changes in soccer players' names of Brazilian National soccer team}

\author{
Vinícius Pereira de Souza Cruz \\ Universidade Federal de Minas Gerais \\ https://orcid.org/0000-0001-6144-018X \\ vinicius.cruz986@gmail.com \\ Eduardo Tadeu Roque Amaral \\ Universidade Federal de Minas Gerais \\ https://orcid.org/0000-0001-9416-3676 \\ eduamaralbh@ufmg.br
}

\section{Resumo}

Este artigo apresenta uma análise de antropônimos oficiais e não oficiais de jogadores da Seleção Brasileira do período compreendido entre 1958 e 2018. O marco teórico se apoia tanto em estudos de Onomástica, como Amaral (2011), Amaral e Seide (2020), Bajo Pérez (2002), Becker (2018), Fernández Leborans (1999), Urrutia e Sánchez (2009), Van Langendonck (2007), quanto em estudos sobre o futebol brasileiro, como Rodrigues (2010) e Caetano e Rodrigues (2009). Os dados analisados são os nomes das listas de jogadores convocados nesse período para os jogos mundiais. Esses nomes são classificados com o objetivo de observar a variação e a mudança ao longo do tempo. Os resultados indicam um predomínio de nomes oficiais em quase todos os anos, bem como uma maior tendência contemporânea às variantes mais formais dos nomes.

Palavras-chave: Seleção Brasileira, jogadores de futebol, antropônimos.

\begin{abstract}
This paper presents an analysis of official and unofficial anthroponyms of soccer players from the Brazilian National team from 1958 to 2018. The theoretical framework is based on onomastic studies, such as Amaral (2011), Amaral e Seide (2020), Bajo Pérez (2002), Becker (2012), Fernández Leborans (1999), Urrutia and Sánchez (2009), Van Langendonck (2007), Fernández Leborans (1999) as well as on analyzes about the Brazilian soccer such as Rodrigues (2010) and Caetano and Rodrigues (2009). The data analyzed are the names from the lists of players selected in that period to compete in the World Cup. These names are classified in order to observe the variation and the change over time. The results indicate a predominance of official names in almost every year, as well as a greater contemporary trend towards more formal variants of names.
\end{abstract}

Keywords: Brazilian National soccer team, soccer players, anthroponyms. 


\section{Introdução}

O escritor Nelson Rodrigues, em seu livro de crônicas A pátria de chuteiras, faz menção a uma identidade nacional brasileira criada pela forma alegre de se jogar o futebol e de se consolidar como potência esportiva (RODRIGUES, 2013). Nomes como Pelé, Garrincha e outros que eternizaram nossos jogadores são emblemáticos para a nossa história. Se, por um lado, esses jogadores contribuem para a história do futebol brasileiro, por outro, seus nomes, formados por apelidos, constituem elementos importantes para o estudo da antroponímia brasileira.

O tema dos nomes dos jogadores suscita curiosidade da comunidade futebolística, o que se observa nos questionamentos sobre o possível desaparecimento de apelidos nos nomes dos atletas. O ex-dirigente esportivo do São Paulo FC, Marco Aurélio Cunha, por exemplo, sugere uma perda cultural do futebol (NÓBREGA, 2018). Contudo, no período em análise, muitos fatores sociais podem ter colaborado para essas mudanças, desde a acentuada discussão sobre o bullying no final dos anos 90, como cita Perisse (2016), até a midiatização esportiva. Sobre este último, a lógica residiria nas transmissões de jogos que proporcionaram visibilidade exponencial da imagem do jogador (CAETANO; RODRIGUES, 2009).

Considerando a importância dos nomes de jogadores para a antroponímia do país, este artigo analisa uma amostra de dados da Seleção Brasileira de futebol masculino em suas participações em Copas do Mundo entre 1958 e 2018 pela lista de convocados. Justifica a escolha deste período para esta análise o surgimento de uma identidade nacional criada pelo futebol e, além disso, o fato de que este período marca o processo de modernização esportiva no contexto da globalização, caracterizada pelas transferências internacionais dos atletas após os anos 70 .

Para a análise, o trabalho se apoia nas contribuições teóricas de Amaral (2011), Amaral e Seide (2020), Bajo Pérez (2002), Becker (2018), Fernández Leborans (1999), Urrutia e 
Onomástica Desde América Latina, n.3, v.2, janeiro - junho, 2021, p. 101 -118 ISSN 2675-2719

Sánchez (2009) e Van Langendonck (2007), que definem e explicam as funções dos antropônimos, relacionando-os ao seu emprego social. Também são considerados os trabalhos de Rodrigues (2010) e Caetano e Rodrigues (2009) sobre o futebol, além de matérias esportivas relacionadas com a temática deste artigo. Na próxima seção, explicam-se os pressupostos teóricos.

\section{Pressupostos teóricos}

Os nomes próprios de pessoa, também chamados de antropônimos, juntamente com os nomes de lugares, denominados topônimos, e de outras entidades, constituem o objeto de estudo da Onomástica. Quando se observa a influência de fatores sociais no conjunto dos nomes próprios, alguns autores falam em Sócio-onomástica ${ }^{1}$. De acordo com Ainiala (2016), a pesquisa Sócio-onomástica introduziu a questão da variação na onomástica. Assume-se, assim, nessa vertente variacionista de estudos dos nomes próprios, que os nomes próprios não são estáticos, constantes ou estáveis, mas variáveis.

McClure (1981) analisa, por exemplo, formas variantes que não fazem parte dos usos oficiais e afirma que, em alguns contextos sociais, as pessoas nomeadas têm certo grau de escolha do nome pelo qual desejam ser tratadas. Para o autor, já que a nomeação é um ato social, a variação na nomeação das pessoas reflete uma variação em papéis sociais, nas atitudes e no contexto. No campo da chamada variação situacional, Ainiala (2016) destaca que o mesmo indivíduo pode variar o nome, de acordo com o contexto situacional. Esse é um pressuposto que se assume neste trabalho, ao considerar que muitos jogadores recebem uma denominação diferente do nome civil que possuem.

\footnotetext{
${ }^{1}$ Embora seja muito difícil dissociar o estudo dos nomes próprios de questões sociais, Gary-Prieur (2016) defende uma análise que considere exclusivamente fatos linguísticos.
} 
Onomástica Desde América Latina, n.3, v.2, janeiro - junho, 2021, p. 101 -118 ISSN 2675-2719

Ao analisar dados principalmente do neerlandês e partindo de critérios semânticopragmáticos, Van Langendonck (2007) distingue o uso primário versus secundário e oficial versus não oficial dos nomes próprios. Seu argumento para distingui-los se apoia no uso do termo primário para aqueles que preenchem funções principais dos nomes pessoais: direcionamento, identificação e uma ampla possibilidade de subcategorização quanto ao gênero e expressividade. Entre os nomes primários e oficiais, o autor inclui os prenomes e os sobrenomes. No conjunto dos nomes secundários e oficiais, estaria, por exemplo, o nome de família empregado como nome individual. Como nomes não oficiais, teríamos os apelidos (bynames). Ainda dentro da classificação de Van Langendonck (2007: 187-189), o autor observa que, pelo menos no padrão europeu, a partir da combinação sintática, os nomes aparecem em estruturas como (prenome + sobrenome $),($ prenome + apelido $)$ ou (apelido + prenome) e assim por diante.

A divisão proposta por Van Langendonck (2007) é retomada por Amaral (2011) e Amaral e Seide (2020), que analisam dados do português brasileiro. Entretanto, esses trabalhos incluem uma série de antropônimos que mostram a diversidade de formas de denominação de pessoas no Brasil. Amaral e Seide (2020), por exemplo, chegam a propor quatorze tipos de antropônimos em sua proposta tipológica (prenome; sobrenome; agnome; apelido (ou alcunha, ou cognome); hipocorístico; pseudônimo; codinome; heterônimo; nome artístico (e nome de palco); nome de guerra; nome religioso; nome social; nome de urna; nome parlamentar).

Um fato relevante destacado pelos estudos citados corresponde à inclusão dos derivados diminutivos e aumentativos no conjunto dos antropônimos. Isto pode ser exemplificado, no Brasil, com as derivações do nome Ronaldo, no formato aumentativo (Ronaldão) e no formato diminutivo (Ronaldinho). Tais formas, por apresentarem semelhança formal com o nome civil, constituem os chamados hipocorísticos. 
Onomástica Desde América Latina, n.3, v.2, janeiro - junho, 2021, p. 101 -118 ISSN 2675-2719

Contribui para este artigo a divisão proposta por Amaral (2011) entre ortônimos e alônimos. Nessa classificação, o autor explica que os primeiros correspondem, no Brasil, aos prenomes e sobrenomes que configuram os nomes civis, ao passo que os segundos "são aqueles antropônimos que não correspondem com os nomes oficiais garantidos pela legislação e atribuídos ao indivíduo no registro civil”" (AMARAL, 2011: 71-72). Nesta última categoria, por exemplo, estão presentes os hipocorísticos e apelidos que serão, mais adiante, retomados a partir de Urrutia e Sánchez (2009) e Bajo Pérez (2002).

Com relação aos ortônimos (nomes oficiais), Van Langendonck (2007) e Amaral (2011) são coincidentes em destacar que eles são registrados em instituições oficiais, sendo atribuídos através do ato de registro cartorial. Esses nomes, que compreendem o prenome (simples ou composto $^{2}$, o(s) sobrenome(s) e, por vezes, o agnome (por exemplo: Júnior, Filho, Sobrinho, Neto), passam a identificar as pessoas em diversos contextos formais e sociais.

Van Langendonck (2007: 190), em sua análise pragmática, considera que o prenome tem caráter individual, pois vê, como regra geral, que se chame as pessoas por ele e não pelo sobrenome, o qual, na realidade, designa a família do portador. Em outras palavras, o prenome faz menção ao indivíduo como portador único daquele nome, enquanto o sobrenome, por ser de ordem patronímica ou matronímica, não possui este mesmo caráter individualizador, sendo visto como forma de tratamento mais formal.

Nos fragmentos de (1) a (4), extraídos aleatoriamente de textos da imprensa, encontramse exemplos de ortônimos de jogadores brasileiros.

(1) Quando questionado sobre Neymar, o uruguaio foi bem sucinto. O atacante brasileiro é especulado para retornar ao Barcelona. (TERRA, 2019, grifo nosso)

\footnotetext{
${ }^{2}$ Há autores que distinguem o prenome composto (formas consagradas pelo uso e consideradas um nome só) do nome justaposto (formas que constituem um conjunto não usual) (cf. Amaral e Seide, 2020: 77).
} 
(2) O Paris Saint-Germain confirmou o desligamento do lateral Daniel Alves, que anunciou sua saída do clube francês em texto publicado em seu perfil no Instagram na madrugada de hoje. (UOL, 2019, grifo nosso)

(3) Quando chegou à Ferroviária, no início do mês de junho de 2018, para exercer a função de diretor executivo de futebol, Roque Júnior deixou claro que tinha como objetivo ajudar a organizar o clube, voltando a participar de competições nacionais. (GUIMARÃES, 2019, grifo nosso).

(4) O fã de Taffarel de 33 anos é o retrato de uma equipe que se conhece muito bem. (UOL, 2019, grifo nosso).

Observa-se que há uma grande variação entre os antropônimos civis utilizados para nomeá-los. Para o jogador Neymar, utiliza-se o prenome; para Daniel Alves, prenome e sobrenome; para Roque Júnior, sobrenome e agnome; para Taffarel, último sobrenome, conforme esquematizado no quadro 1.

Quadro 1 - Nomes civis completos dos jogadores mencionados nos exemplos (1) a (4)

\begin{tabular}{|l|c|c|c|c|}
\hline & prenome & sobrenome & sobrenome & agnome \\
\hline (1) Neymar & Neymar & da Silva & Santos & Júnior \\
\hline (2) Daniel Alves & Daniel & Alves & da Silva & \\
\hline (3) Roque Júnior & José Vítor & Roque & & Júnior \\
\hline (4) Taffarel & Cláudio André & Mergen & Taffarel & \\
\hline
\end{tabular}

Por outro lado, os alônimos, como nomes não pertencentes ao registro civil, compreendem uma categoria bastante heterogênea. Esta pesquisa se restringe aos hipocorísticos e aos apelidos, comuns entre os jogadores brasileiros. Ambos são considerados subcategorias do nome próprio e se destacam pela informalidade no tratamento entre pessoas.

Bajo Pérez (2002: 32) trata os hipocorísticos, no caso da língua espanhola, como alterações e abreviações dos nomes pessoais. Na análise da autora, são formas com valores expressivos (carinhosos, pejorativos, irônicos...) que servem para facilitar a pronúncia ou tornar o antropônimo oficial mais breve, mais divertido, mais íntimo, etc. Por esta alteração fonética, que se avalia como facilitadora na pronúncia infantil, estes nomes comportam formas 
Onomástica Desde América Latina, n.3, v.2, janeiro - junho, 2021, p. 101 -118 ISSN 2675-2719

diminutivas (ex: Ronaldinho, Zinho) e aumentativas (ex: Ronaldão, Chicão). Outro ponto importante ressaltado pela autora (2002: 34) é que sempre surgem novos hipocorísticos que se supõe serem de conhecimento do nativo da própria língua.

Na avaliação de Fernández Leborans (1999: 81), essas formas se dão por convenções da língua e não necessariamente por fatores etários. Urrutia e Sánchez (2009: 159-162) classifica, no espanhol americano, alguns tipos de estruturas destes hipocorísticos, que consistem em supressões iniciais, intermediárias e finais dos nomes. Entretanto, ainda que apresente semelhanças com o português brasileiro ao menos nos nomes da amostra deste artigo, nem todos seriam aplicáveis à sua classificação. Para este trabalho, admitem-se as classificações de encurtamento inicial (José > Zé, Donizetti > Zetti), encurtamento final (Eduardo > Edu, Dorival $>$ Doriva $)$ e encurtamento inicial-intermediário $(\text { Eduardo }>A d o)^{3}$.

No que concerne aos apelidos, Urrutia e Sánchez (2009: 155-157) explicam que são nomes que atendem características biológicas e familiares, no âmbito afetivo. São diferentes dos hipocorísticos, pois atendem motivações que ressaltam características físicas ou psicológicas, de maneira irônica por revelar aspectos negativos. Também cabe a importância de ressaltar que são nomes eleitos pela coletividade, quer dizer, nomes dados, geralmente, pelo círculo social do indivíduo. Becker (2018) e Van Langendonck (2007), por sua vez, coincidem em afirmar que essas características, na Idade Média, tiveram funções de suprirem carências de nomes próprios. Tendo em vista estas carências, que têm relação quanto à identificação de indivíduos, os apelidos serviram, inclusive, para a formação de prenomes e sobrenomes naquela época.

Van Langendonck (2007: 193), porém, adverte que esta forma de nomear, nos tempos modernos, tem diminuído tanto em grandes centros quanto em comunidades menores. É

\footnotetext{
${ }^{3}$ Para um estudo contrastivo entre formas hipocorísticas do português brasileiro e do lituano, veja-se Seide e Petrulioné (2020).
} 
Onomástica Desde América Latina, n.3, v.2, janeiro - junho, 2021, p. 101 -118 ISSN 2675-2719

possível que esta afirmação seja correta, levando-se em consideração que constitui uma hipótese corrente na comunidade futebolística e que motiva esta pesquisa.

No que se referem às escalações da Seleção Brasileira, ao longo do período investigado, apelidos como Garrincha, Dinamite, Branco, Chulapa são bons destaques. Mesmo que não sejam precisas suas motivações, podem sugerir características físicas e capacidades técnicas na potência para chutar a bola. Também são destacáveis gentílicos como Paulista, Gaúcho e Baiano, que aludem a regiões de origem dos jogadores. Em muitos casos, tem-se apenas um elemento antroponímico formando o nome do jogador. Amaral e Seide (2020: 89) ressaltam que a formação de antropônimos de personalidades por apenas um elemento parece ser comum no meio esportivo, mas não chegam a desenvolver o tema. Os autores destacam que esses nomes muitas vezes derivam de apelidos ou de hipocorísticos e citam os exemplos de Tande (< Alexandre Ramos Samuel, ex-jogador de voleibol) e Kaká (< Ricardo Izecson dos Santos Leite, futebolista). Na análise de resultados, voltaremos a comentar esses nomes.

\section{Metodologia e resultados quantificados}

A amostra de dados para este artigo se baseia na composição da Seleção Brasileira no período de 1958 a 2018 para a participação em Copas do Mundo. Foram consideradas as listas dos nomes convocados para os torneios disputados. Como fonte de dados, recorremos ao site Imortais do Futebol, que disponibiliza na seção Curiosidades Históricas, sob o título Todos os Convocados do Brasil nas Copas, nomes dos jogadores da seleção nacional que fizeram parte delas desde 1930.

A escolha deste período se justifica pela inserção da Seleção Brasileira entre as maiores potências do futebol. Além disso, contempla os nomes de Pelé e Garrincha, sendo nomes não oficiais considerados ícones no futebol nacional, marcados pelas características técnicas e pela conquista da Copa do Mundo de 1958. Fatores como a modernização do esporte no país, transmissões de jogos e transferências de jogadores no mercado globalizado são vistos como 
possíveis influências na mudança do perfil de nome dos atuais jogadores. Esta hipótese ganhou mais força na Copa de 2018, em virtude de comentários esportivos sobre a ausência de apelidos na lista de convocados, como na publicação de Nóbrega (2018).

Para a classificação dos nomes, este trabalho divide os antropônimos em nomes oficiais, tendo nesta categoria prenomes, sobrenomes e agnomes, e nomes não oficiais, restritos aos apelidos e hipocorísticos, tal como exposto na seção anterior. Por fim, cabe ressaltar que os nomes dos jogadores serão analisados de acordo com o registro do nome de $\mathrm{jogo}^{4}$, quer dizer, de acordo com o que consta na relação dos convocados publicada no site informado.

\section{Resultados e análise}

Nesta seção, apresentamos os resultados e análises da amostra com base nos nomes dos jogadores, considerando os critérios mencionados em nossa metodologia. O quadro abaixo apresenta a porcentagem das ocorrências de nomes oficiais e de nomes não oficiais por Copas:

Quadro 2 - Distribuição dos nomes oficiais e não oficiais dos jogadores da Seleção Brasileira nas Copas de 1958 a 2018 (\%)

\begin{tabular}{|l|l|l|}
\hline \multicolumn{1}{|c|}{ Ano } & \multicolumn{1}{|c|}{ Nomes oficiais } & \multicolumn{1}{c|}{ Nomes não oficiais } \\
\hline 1958 & $59,1 \%$ & $40,9 \%$ \\
\hline 1962 & $63,6 \%$ & $36,4 \%$ \\
\hline 1966 & $63,6 \%$ & $36,4 \%$ \\
\hline 1970 & $63,6 \%$ & $36,4 \%$ \\
\hline 1974 & $54,5 \%$ & $45,5 \%$ \\
\hline 1978 & $59,1 \%$ & $40,9 \%$ \\
\hline 1982 & $63,6 \%$ & $36,4 \%$ \\
\hline 1986 & $72,7 \%$ & $27,3 \%$ \\
\hline 1990 & $50 \%$ & $50 \%$ \\
\hline
\end{tabular}

\footnotetext{
${ }^{4}$ A expressão nome de jogo é uma escolha dos autores para a referência aos nomes que aparecem nas escalações em veículos como televisão, rádio, jornais, revistas e páginas especializadas.
} 
Onomástica Desde América Latina, n.3, v.2, janeiro - junho, 2021, p. 101 -118 ISSN 2675-2719

\begin{tabular}{|l|l|l|}
\hline 1994 & $50 \%$ & $50 \%$ \\
\hline 1998 & $63,6 \%$ & $36,4 \%$ \\
\hline 2002 & $60,8 \%$ & $39,2 \%$ \\
\hline 2006 & $43,5 \%$ & $56,5 \%$ \\
\hline 2010 & $78,3 \%$ & $21,7 \%$ \\
\hline 2014 & $78,3 \%$ & $21,7 \%$ \\
\hline 2018 & $82,6 \%$ & $17,4 \%$ \\
\hline
\end{tabular}

O gráfico 1, que permite visualizar melhor os resultados acima por meio de décadas, mostra que, no período selecionado para este trabalho, há predominância dos nomes oficiais sobre os nomes não oficiais. Com exceção das duas primeiras copas dos anos 90, que sinaliza uma igualdade do uso de não oficiais com os oficiais, o uso considerado formal costuma ser preferencial.

Gráfico 1 - Variação dos antropônimos dos jogadores da Seleção Brasileira entre 1958 e 2018 (\%)

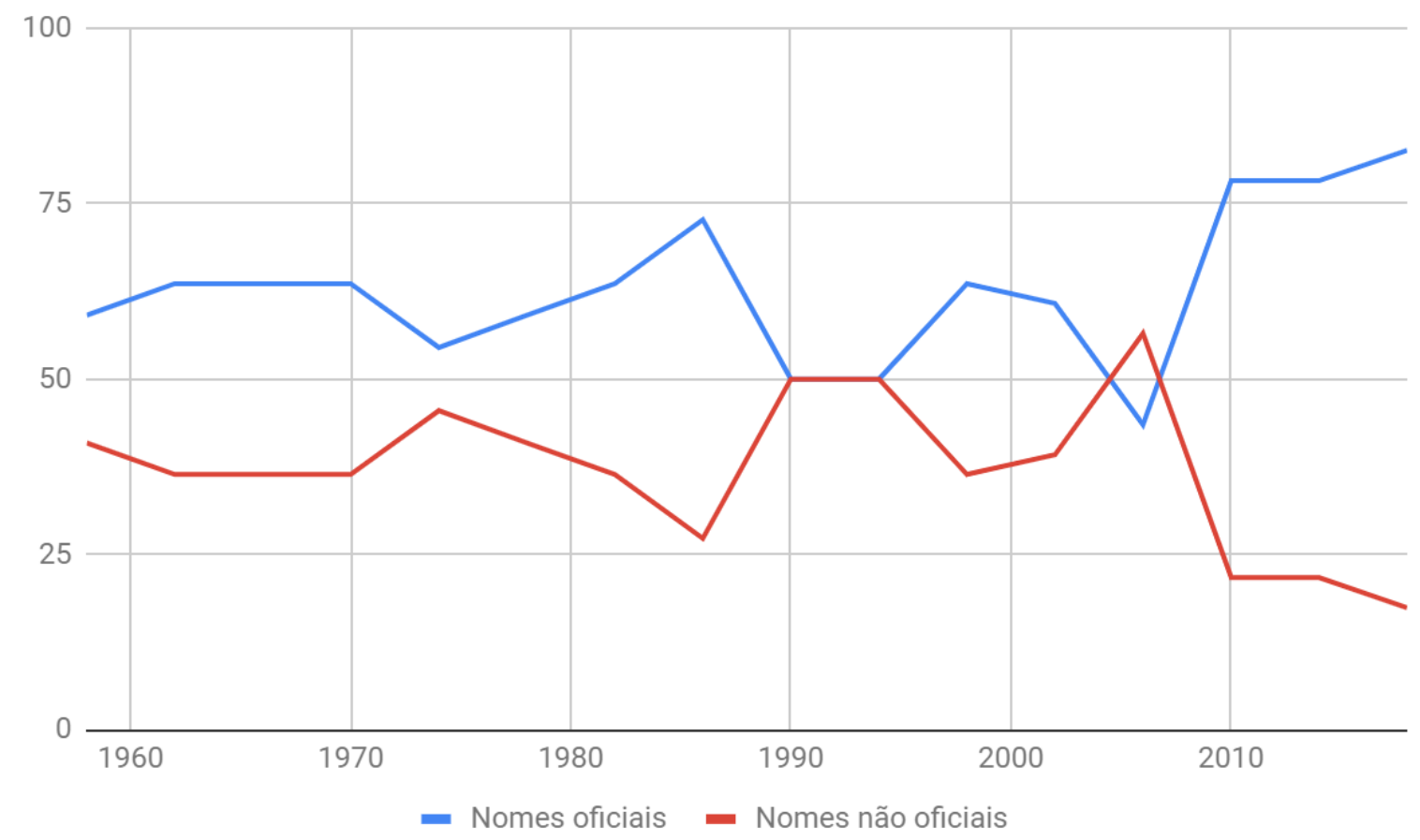


Onomástica Desde América Latina, n.3, v.2, janeiro - junho, 2021, p. 101 -118 ISSN 2675-2719

Conforme o gráfico apresentado, observam-se alguns fenômenos interessantes de variações apresentadas pelas participações do país nas copas. Para analisá-los, podemos dividir o período em duas fases, de acordo com as respectivas participações nos mundiais:

a) Primeira fase (1958 a 1986)

Inserção e consolidação como potência mundial no futebol.

b) Segunda fase (1990 a 2018)

Modernização, midiatização e transferências internacionais.

A primeira fase abarca as três primeiras conquistas do Brasil (1958, 1962 e 1970) e a aparição de nomes não oficiais, como Pelé, Tostão, Garrincha, Zico, Dinamite, Caju, Chulapa, entre outros, que se tornaram referentes por suas características ofensivas associadas ao estilo de jogo brasileiro. Caetano e Rodrigues (2009: 5-6) analisam esta etapa como parte do processo de modernização do futebol brasileiro. Segundo os autores, o período de 1950 - 1970 marca a construção da identidade nacional pelo viés do futebol. Neste aspecto, os nomes mencionados podem ressaltar o caráter irreverente do brasileiro na prática do jogo, que prima pelo engenho e sua técnica.

No pós 1970, segundo os mesmos autores, o futebol se abre à incrementação financeira, através dos salários dos jogadores, da visibilidade através das transmissões televisivas e das transferências de clubes. Provavelmente, esses fatores corroboraram para a predominância do uso de nomes oficiais na totalidade dos convocados nos anos 80. A seguir, apresenta-se um quadro exemplificativo com as escalações de 1982 e de 1986 e suas respectivas distinções entre nomes oficiais (negrito) e não oficiais (itálico):

Quadro 3 - Nomes oficiais e não oficiais dos jogadores das seleções de 1982 e de $1986^{5}$

\begin{tabular}{|c|c|c|}
\hline Ano da & Nomes oficiais & Nomes não oficiais \\
Seleção & & \\
Brasileira & & \\
\hline
\end{tabular}

\footnotetext{
${ }^{5}$ A escolha da ordem dos nomes dos autores nos quadros 3, 4, 5 e 6 se deve à tradição brasileira nas escalações de acordo com suas respectivas posições (goleiros, defensores, meias e atacantes), tal como aparecem nos meios de comunicação.
} 


\begin{tabular}{|c|c|c|}
\hline 1982 & $\begin{array}{c}\text { Waldir Peres, Paulo Sérgio, Carlos, Oscar, } \\
\text { Leandro, Júnior, Edevaldo, Sócrates, Falcão, } \\
\text { Batista, Renato, Paulo Isidoro, Éder Aleixo, } \\
\text { Dirceu. }\end{array}$ & $\begin{array}{c}\text { Luisinho, Juninho Fonseca, Edinho, Pedrinho, } \\
\text { Toninho Cerezo, Zico, Serginho Chulapa, } \\
\text { Roberto Dinamite. }\end{array}$ \\
\hline 1986 & $\begin{array}{c}\text { Carlos, Paulo Victor, Emerson Leão, Oscar, } \\
\text { Júlio César, Mauro Galvão, Édson, Josimar, } \\
\text { Falcão, Júnior, Sócrates, Elzo, Silas, Valdo, } \\
\text { Casagrande, Edivaldo. }\end{array}$ & $\begin{array}{c}\text { Edinho, Branco, Alemão, Zico, Muller, } \\
\text { Careca. }\end{array}$ \\
\hline
\end{tabular}

Por pertencerem à categoria mais formal entre os nomes pessoais, esta predominância, possivelmente, representa a tentativa do futebol, por meio dos nomes próprios, de romper com certos preconceitos sociais, com relação à prática esportiva profissional. Além disso, a representação nacional em eventos internacionais viabiliza a divulgação de certa imagem do país e, porventura, opta-se por certa sobriedade nestas aparições.

Por outro lado, na segunda fase, a partir de 1990, inicia-se um processo de modernização do nosso futebol, em que a globalização permite maior exportação de jogadores para grandes mercados estrangeiros. Grande parte dos jogadores convocados, a partir desta época, defende clubes estrangeiros.

Nesta divisão, as copas de 1990 e 1994 apresentam um resultado mais equilibrado, tendo $50 \%$ de nomes oficiais e $50 \%$ não oficiais. Vejamos a seguir o quadro exemplificativo dessas duas seleções, seguindo os mesmos critérios de distinção de nomes adotados no quadro anterior:

Quadro 4 - - Nomes oficiais e não oficiais dos jogadores das seleções de 1990 e de 1994

\begin{tabular}{|c|c|c|}
\hline $\begin{array}{c}\text { Ano da } \\
\text { Seleção } \\
\text { Brasileira }\end{array}$ & Nomes oficiais & Nomes não oficiais \\
\hline 1990 & $\begin{array}{c}\text { Taffarel, Acácio, Ricardo Gomes, Mozer, } \\
\text { Aldair, Ricardo Rocha, Mauro Galvão, } \\
\text { Bismarck, Valdo, Silas, Romário. }\end{array}$ & $\begin{array}{c}\text { Zé Carlos, Jorginho, Branco, Mazinho, Dunga, } \\
\text { Alemão, Tita, Careca, Bebeto, Müller, Renato } \\
\text { Gaúcho. }\end{array}$ \\
\hline 1994 & $\begin{array}{c}\text { Taffarel, Gilmar Rinaldi, Ricardo Rocha, } \\
\text { Aldair, Márcio Santos, Leonardo, Mauro } \\
\text { Silva, Raí, Paulo Sérgio, Romário, Ronaldo. }\end{array}$ & $\begin{array}{c}\text { Zetti, Ronaldão, Jorginho, Branco, Cafu, } \\
\text { Dunga, Zinho, Mazinho, Bebeto, Müller, Viola. }\end{array}$ \\
\hline
\end{tabular}


A princípio, esta igualdade pode retratar, quanto aos nomes não oficiais, o uso do jogador brasileiro como mão de obra essencial para os clubes estrangeiros, principalmente europeus, no início dos anos 90. Esta imagem se contrapõe com a brusca mudança de perfil a partir de 2010. O ano de 2006 se interpreta como excepcional, pois foi a única destas seleções a ter predominância de nomes não oficiais, com aproximadamente 56\% de ocorrências, como vemos no quadro a seguir:

Quadro 5: Nomes oficiais e não oficiais de jogadores da Seleção Brasileira de 2006

\begin{tabular}{|c|c|c|}
\hline $\begin{array}{c}\text { Ano da } \\
\text { Seleção } \\
\text { Brasileira }\end{array}$ & Nomes oficiais & Nomes não oficiais \\
\hline 2006 & $\begin{array}{c}\text { Rogério Ceni, Júlio César, Lúcio, Juan, } \\
\text { Roberto Carlos, Gilberto, Emerson, } \\
\text { Gilberto Silva, Adriano, Ronaldo. }\end{array}$ & $\begin{array}{c}\text { Dida, Cris, Cafu, Cicinho, Kaká, Ronaldinho } \\
\text { Gaúcho, Zé Roberto, Mineiro, Juninho } \\
\text { Pernambucano, Ricardinho, Fred, Robinho. }\end{array}$ \\
\hline
\end{tabular}

Contudo, ao longo desta segunda parte, a preferência pelo uso de nomes oficiais se confirma e se acentua, sobretudo, nas copas de 2010 a 2018, em que os índices se aproximam dos $80 \%$ das ocorrências desta categoria. Vejamos o quadro 6:

Quadro 6 - Nomes oficiais e não oficiais de jogadores das seleções de 2010 e de 2018

\begin{tabular}{|c|c|c|}
\hline $\begin{array}{c}\text { Ano da } \\
\text { Seleção } \\
\text { Brasileira }\end{array}$ & Nomes oficiais & Nomes não oficiais \\
\hline 2010 & $\begin{array}{l}\text { Júlio César, Gomes, Lúcio, Juan, Thiago } \\
\text { Silva, Maicon, Michel Bastos, Daniel } \\
\text { Alves, Gilberto, Felipe Melo, Elano, } \\
\text { Gilberto Silva, Josué, Ramires, Júlio } \\
\text { Baptista, Kléberson, Luis Fabiano, Nilmar. }\end{array}$ & Doni, Luisão, Kaká, Robinho, Grafite. \\
\hline 2014 & $\begin{array}{l}\text { Jefferson, Júlio César, Victor, Thiago } \\
\text { Silva, David Luiz, Dante, Henrique, Daniel } \\
\text { Alves, Marcelo, Maicon, Maxwell, Oscar, } \\
\text { Ramires, Willian, Luis Gustavo, Hernanes, } \\
\text { Neymar, Bernard. }\end{array}$ & Fernandinho, Paulinho, Hulk, Fred, Jô. \\
\hline 2018 & $\begin{array}{l}\text { Alisson, Cassio, Ederson, Thiago Silva, } \\
\text { Miranda, Pedro Geromel, Filipe Luís, } \\
\text { Marcelo, Danilo, Fagner, Casemiro, } \\
\text { Renato Augusto, Philippe Coutinho, }\end{array}$ & Marquinhos, Paulinho, Fernandinho, Fred. \\
\hline
\end{tabular}


Willian, Douglas Costa, Gabriel Jesus, Neymar, Roberto Firmino, Taison.

É provável que essa mudança no nome, exemplificada no quadro acima, tenha como panorama seu uso nos países receptores destes jogadores que, possivelmente, promovem esta adequação. Em matéria publicada no $O$ Globo, sobre a possibilidade da conquista do hexacampeonato, um jornalista britânico observa esta preferência pelo uso dos nomes oficiais dos jogadores:

Neste ano, não há nenhum Tostão ou Hulk, ou qualquer um dos sete anões, como o Dunga. Em seus lugares estão Fred (forma familiar de Frederico), Douglas e Marcelo, nomes que não soariam estranhos em algum centro empresarial britânico', escreveu Downie (NÓBREGA, 2018).

Na mesma publicação, se destaca, também, a fala do cronista Simas sobre o processo histórico do futebol brasileiro, desde a sua origem popular até a sua modernização, recordando a obra do historiador Joel Rufino dos Santos. Nela, segundo o cronista, é citada a popularização do futebol, concorrente com a capoeira, como ambiente propício para a criação dos apelidos. Sua observação, claramente, vem do uso de espaços públicos, como exemplo de ruas e praças, para suas respectivas práticas esportivas, que promovem aglomerações de indivíduos como forma de lazer e sociabilidade, além das tradições portuguesas e africanas que se refletem nos nomes dados.

Simas também comenta que o contexto da globalização influi na mudança de perfil dos nomes, fazendo com que jovens atletas sejam inseridos no mercado estrangeiro. Caetano e Rodrigues (2009: 3) lembram que, além disso, fatores como a Lei Pelé e o Caso Bosman foram determinantes na mudança do futebol, pois de forma concomitante promoveram a flexibilização das transferências internacionais de jogadores brasileiros e a maior aceitação de jogadores estrangeiros em continente europeu. Assim, é bastante provável que a adaptação mercadológica influa no perfil dos nomes destes jogadores. 
Onomástica Desde América Latina, n.3, v.2, janeiro - junho, 2021, p. 101 -118 ISSN 2675-2719

Outro fator, salientado por Marco Aurélio Cunha, corresponde à profissionalização do futebol e ao bullying (NÓBREGA, 2018). Segundo o dirigente, justifica-se o "politicamente correto" para não fazer atribuições ao físico do jogador. Além disso, os "nomes completos" criam uma relação mais impessoal, pois diminuem a proximidade afetiva que se estabelecia, em outra época, através dos apelidos. É plausível que esta formalidade imposta dos nomes oficiais dê a impressão de maior profissionalismo dentro do mercado esportivo.

\section{Considerações finais}

O imaginário de que o futebol brasileiro sempre foi atrelado aos nomes não oficiais, que, neste trabalho, correspondem aos apelidos e hipocorísticos de jogadores, não se confirma pelos resultados apresentados. Talvez essa impressão, provavelmente midiática, parta dos nomes que mais se destacaram em determinada época e, consequentemente, chamaram mais a atenção dos falantes. Com isso, a impressão de ausência ou pouca ocorrência desses nomes, atualmente em nosso futebol, gera este estranhamento por parte dos jornalistas e do seu público. Cabe ressaltar que esta afirmação se embasa no ambiente restrito da convocação de jogadores para representar a Seleção Nacional em determinado período, não fazendo jus à realidade de milhares de jogadores brasileiros.

Os resultados obtidos demonstram uma preferência por maior formalidade como forma de representatividade nacional nestas competições. Também retrata, a levar em conta os dados a partir de 2010, que nosso futebol está cada vez mais alinhado com o mercado estrangeiro, tendo aproximadamente $80 \%$ de atletas registrados com nomes oficiais e muitos deles atuando no exterior. Tais números, sob esta análise, refletem possíveis rupturas com o nosso passado futebolístico, sempre avaliado como engenhoso e irreverente pelos seus nomes e estilo de jogo. Esta análise faz coro às observações críticas de Rodrigues (2010) e do ex jogador Paulo César Caju (RIBEIRO, [s. d.]), com relação com o nosso estilo de jogo hoje. 
Onomástica Desde América Latina, n.3, v.2, janeiro - junho, 2021, p. 101 -118 ISSN 2675-2719

Tendo em vista que os espaços para a prática esportiva estão progressivamente mais institucionalizados, com centros de treinamentos que visam à formação profissional (RODRIGUES, 2010: 342-343), voltada à prática comercial, esses fatores tendem a favorecer a diminuição de tratamentos informais. Este argumento, em escala menor, se aproxima do argumento de Van Langendonck (2007) em relação à tendência da redução dos bynames (nomes não oficiais), principalmente dos apelidos, nos grandes centros urbanos. Considerando que o crivo convocatório passa pela concepção de grandes clubes e grandes centros do futebol, seu argumento adquire força.

Quanto às memórias afetivas da comunidade futebolística sobre a ausência de nomes não oficiais no atual contexto, provavelmente estão relacionadas a jogadores de destaque, em determinada posição ou função, na Seleção Brasileira. Dessa abstração, podem contribuir, também, as conquistas obtidas nos anos 90 e 2000, épocas em que seu uso chegou a elevadas ocorrências nos registros dos jogadores. Todavia, este artigo se restringe apenas aos dados escolhidos para a análise, de forma que não esgota os questionamentos e cabendo futuras ampliações em outras pesquisas.

Recebido em 30/08/2020

Aceito em 28/09/2020

Publicado em em 17/12/2020

\section{Referências bibliográficas}

Ainiala, T. (2016). Names in society. In: HOUGH, C. (Ed.). The Oxford handbook of names and naming (371-381). Oxford: Oxford University Press.

Amaral, E. T. R. (2011). Contribuições para uma tipologia de antropônimos do português brasileiro. Alfa Revista de Linguística, 55 (2), 63-82.

Amaral, E. T. R.; Seide, M. S. (2020). Nomes próprios de pessoa: introdução à antroponímia brasileira. São Paulo: Blucher.

Bajo Pérez, E. (2002). La caracterización morfosintáctica del nombre propio. La Coruña: Toxosoutos. 
Becker, L. (2018) Nombres de persona en español / PersonennamenimSpanischen: historia, situación actual y onomástica popular / Geschichte, aktuelleSituationundLaienonomastik. Berlim: Peter Lang.

Caetano, S. M. \& Rodrigues, F. X. F. (2009). Modernização do futebol brasileiro e a transferência internacional de jogadores brasileiros. In: XIV Congresso Brasileiro de Sociologia, 28-31 jul. 2009, Rio de Janeiro (RJ). Anais... Rio de Janeiro: Sociedade Brasileira de Sociologia, 2009. Recuperado em 29 de maio de 2020 de http://www.sbsociologia.com.br/portal/index.php?option=com_docman\&task=cat_view\&gid $=207 \&$ Itemid $=171$.

Fernández Leborans, M. J. (1999). El nombre propio. In: I. Bosque \& V. Demonte, (Dir.). Gramática descriptiva de la lengua española (77-128). Madrid: Espasa Calpe.

Gama, G. (2018). Todos os convocados do Brasil nas Copas: Curiosidades históricas, 18 mai. 2018. Imortais do futebol. Recuperado em 21 de dezembro de 2018 de https://www.imortaisdofutebol.com/2018/05/18/todos-os-convocados-do-brasil-nas-copas/.

Gary-prieur, M.-N. (2016). Le nom propre como catégorie de lagrammaire. Langue Française, $190(2), 45-64$.

Guimarães, M. (2019). Roque Júnior celebra trabalho na Ferroviária, mas não descarta voltar a ser técnico. Yahoo Esportes, 24 jun. 2019. Recuperado em 19 de junho de 2019 de https://esportes.yahoo.com/noticias/roque-junior-celebra-trabalho-na-ferroviaria-mas-naodescartar-voltar-a-ser-tecnico-210208428.html.

Mcclure, P. (1981). Nicknames and petnames. Linguistic forms and social contexts. Nomina, 5, 63-76.

Nóbrega, B. (2018). Seleção brasileira pode conquistar o hexa sem exibir um único apelido, $O$ Globo, Esportes, 29 jun. 2018. Recuperado em 25 de janeiro de 2019 de https://oglobo.globo.com/esportes/selecao-brasileira-pode-conquistar-hexa-sem-exibir-umunico-apelido-22835918.

Perisse, G. (2016). O histórico e as formas de combate ao bullying no Brasil, Fundação Telefônica Vivo, Notícias, 2016. Recuperado em 18 de setembro de 2020 de http://fundacaotelefonicavivo.org.br/promenino/o-historico-e-as-formas-de-combate-aobullying-no-brasil/.

Ribeiro, F. (s. d.). Língua voraz. In: Museu da pelada, Recuperado em 24 de junho de 2019 de http://www.museudapelada.com/linguavoraz.

Rocha, F. (2017).Garrincha - O anjo driblador. Rádio Botafogo, 18 dez. 2017. Recuperado em 17 junho de 2019 de http://www.radiobotafogo.com.br/garrincha-o-anjo-driblador/.

Rodrigues, F. X. F. (2010). O fim do passe e as transferências de jogadores brasileiros em uma época de globalização. Sociologias, 24, 338-380. 
Rodrigues, N. (2013). A pátria de chuteiras. Rio de Janeiro: Nova Fronteira.

Seide, M. S. Petrulioné, L. (2020). Formação e usos de nomes hipocorísticos no português do Brasil e no idioma lituano. Alfa Revista de Linguística, 64, (1).

Terra. (2019). Cavani deseja o melhor a Neymar e quer permanecer no PSG. Campeonato francês, 25 jun. 2019. Recuperado em 19 de junho de 2019 de https://www.terra.com.br/esportes/futebol/internacional/franca/campeonato-frances/cavanideseja-o-melhor-a-neymar-e-quer-permanecer-nopsg,f828edd1060205c9f7d9e90275b154eb6jztkfl8.html.

Urrutia Cárdenas, H.\&Sánchez Gómez, F. (2009). El nombre propio en el español de América. In: C. Hernández Alonso (Ed.). Estudios lingüísticos del español hablado en América. v. III.1: El sintagma nominal - Parte I (57-306). Madrid: Visor Libros.

UOL. (2019). PSG confirma a saída de Daniel Alves e agradece pelos seus dois anos no clube. Uol esporte, 23 jun. 2019. Recuperado em 19 de junho de 2019 de https://esporte.uol.com.br/futebol/ultimas-noticias/2019/06/23/psg-confrma-saida-de-danielalves-e-agradece-pelos-seus-dois-anos-no-clube.htm.

Van Langendonck, W. (2007). Theory and typology of proper names. Berlin: Walter de Gruyter. 